\title{
Escaping to Facebook: youth's engagement with web-based social networks in Sri Lanka
}

\author{
Tharindi Udalagama \\ Department of Sociology, Faculty of Arts, University of Colombo, Colombo 03.
}

\begin{abstract}
This study mainly investigated the reasons leading to the use of web-based social networks among the computer literate youth of Sri Lanka. The web-based social network called Facebook was considered as the field of study for this research carried out in 2009/2010. Supporting itself with 15 case studies, participant observation and secondary information from the Facebook Home Page, this study attempted to explore and understand the usage of Facebook by youth. The major reasons identified by the study were, to gain emotional support and for convenience, i.e. it's free of charge, has no physical or temporal distinction, and the availability of entertainment. This paper discusses these reasons in detail and will explore how the virtual game worlds on Facebook have constructed an alternate reality for the youth to escape to.
\end{abstract}

Keywords: facebook, youth, alternate reality, escapism, virtual games

\section{INTRODUCTION}

Sociologists have defined social networks as ties between individuals based on social, cultural, political or economical reasons that are essentially face-to-face (Mineral, 1968). The computer networks that were established in the 1960s took this definition a few steps further. The internet and the World Wide Web are the sproject executing agenciesrheads of the media revolution that came to be with the networking of computers (Albarran \& Goff, 2003). The 'interconnecting of networks', that is popularly known as the 'internet' is made up of hundreds of thousands of interconnecting computer networks worldwide. It was publicly demonstrated in 1991, and the operating system was termed as the World Wide Web. This became the adhesive that brought together social networks and computer networks which ultimately created web-based social networks.
As Garton, Haythornthwaite \& Wellman (1999) state, when a computer network connects people or organizations, it becomes a social network. Just as a computer network is a set of machines connected by a set of cables, a social network is a set of people (or organizations or other social entities) connected by a set of social relations, such as friendship, co-working, or information exchange. Therefore, any environment that connects people or organizations through computers can be defined as a 'web-based social network'. It was no longer necessary that ties between individuals be face to face, for web-based social networks connected people through interfaces that were virtual rather than actual. This was made possible by the internet and the ultimate result was a borderless, timeless and virtual space that was omnipresent in the world.

A web-based social network is defined as 'a set of persons with whom specific types of support are exchanged, as the set of relationships that are somehow important to a person, or interlocking structures in which supportive and non-supportive interactions both occur' (vanTilburg, 1995; cited in Hinduja and Patchin 2008). Surra and Milardo (1991) define a web-based social network as 'a collection of individuals known by a target person' and consider the network in terms of the 'interdependencies that link partners to their kin, friends and other associates.' These definitions capture the notion that it is essential to understand that each interpersonal relationship occurs within a context of many others in a web-based social network. It is a network which draws support to each incumbent in the network in different ways. However, these interactions may also lead to repulsive interactions as well.

Literature suggests that the virtual spaces that enabled the web-based social networking to take place are termed 
as social network sites (SNSs). Boyd and Ellison (2007) defines social network sites as web-based services that allow individuals to, (1) construct a public or semipublic profile within a bounded system, (2) articulate a list of other users with whom they share a connection, and (3) view and traverse their list of connections and those made by others within the system. The nature and classification of these connections may vary from site to site and for this study Facebook was the social network site under investigation.

The word 'Facebook' has become a part of the everyday vocabulary of the computer literate Sri Lankan youth with access to internet, within a very short period of time since its inception in 2004. The official web page of Facebook defines itself as a 'digital map' of people's real world social connections. There are over 150 million active users globally who have returned to the Facebook site in the last 30 days (Facebook, 2009). An average user has about 100 friends on the site (Facebook, 2009). People world over spends 3 billion minutes on Facebook each day (Facebook, 2009). This begs the questions as to 'why?' they use Facebook and 'what?' they do on Facebook for such a long time. The answer is invariably related to 'what is available' on Facebook. This paper will disclose answers to these queries from the findings of a qualitative inquiry.

\section{METHODOLOGY}

The methodology used to derive information was qualitative as the intention of this study was to learn from the youth of Sri Lanka who are using Facebook as to why they are using Facebook as a medium of social networking. As Patton (1990) states, qualitative inquiry is the most useful when one desires to learn from others. Hence, the best methodology was to carry out a qualitative inquiry.

Fifteen case studies were completed by employing indepth interviews to find out the reasons distinguished by the youth of Sri Lanka on their use of web-based social networks such as Facebook. With this main intention in mind the study also specifically looked into how the youth portray their 'self' on Facebook? has Facebook simulated an alternate reality for the youth? and how has Facebook impacted on the public-private sphere distinction in a youth's life? However, this paper will discuss only the main reasons that were distinguished by the youth for using Facebook and the virtual games on Facebook that seems to have created an alternate reality.
As advocated by Patton (1990), to accomplish such a purpose, a study should employ a sample with 'information rich cases' that one can learn a great deal about the issues of central importance to the purpose of the research. Conforming to Patton, this study interviewed fifteen unmarried Facebook users from the age cohort of 18 to 29 . The sample met the following criteria;

- Being a Facebook user

- Between the ages of 18 to 29

- Currently living in Sri Lanka

- Unmarried

A purposive sample complying with the above criteria was derived from the total population of Facebook users.

A group under the name 'Web-based Social Networks and the Sri Lankan Youth' was created on Facebook, in order to select respondents. A group in Facebook is best understood as a virtual assembly of people who have joined to support the interests the group stands for. Any Facebook user can create a group under any of the interest categories displayed on Facebook and can choose to keep the group open for anyone to join or make it a private group based on invitation only. An open group was created by the above name to find respondents for this study. All details of the research were written on the page of the group for anyone to view. A total of 120 people have joined the group as of date ${ }^{1}$. The fifteen respondents fitting in to the criteria above were derived from 98 people who joined before September 2009. The selected respondents were added to the 'friends list' after gaining their informed consent. (The following link would lead you to the created group: http://www. facebook.com/group.php?gid=118848321894).

The respondents were initially interviewed informally online, using the 'chatting' facility available on Facebook. The 'chat' window allows a Facebook user to chat with his or her online friends. After having the initial conversation with the respondent through Facebook, appointments were made with the respondents to have in-depth interviews in person.

Considering the qualitative nature of the study, a semistructured interview guide was used to collect the data. This method allowed a systematic collection of data from each respondent. It also gave the interviewer the flexibility to decide the sequence and the wording of the questions according to the circumstances. This allowed studying the selected topic in depth and in detail because the data collection was not constrained by predetermined categories of analysis.

\footnotetext{
'as of date' denotes the time the article was originally written in June 2010. The number of members may differ with people dropping out or joining the group.
} 
Participant observation was inevitable as the author was a member of this web-based social network, Facebook. Hence, some information has been derived through field observations of the author during this investigation.

\section{YOUTH AND WEB-BASED SOCIAL NETWORKS}

Many youths have embraced web-based social networking in order to meet their social and relational needs. The internet has augmented the possibility of individuals to meet, interact, and keep in contact with others with whom they have something in common, regardless of demographic or geographic restrictions. Maczewski (2007) in her dissertation 'Understanding how information and communication technologies matter to youth: a network of developmental, social and technological dynamics' positions youth as nexus in online and offline relational networks. She situates youth's experiences of ICT use as emergent from adolescent, societal and technological contexts and within continuous cultural change. The findings of her research pointed out that youth use internet for entertainment, convenience and to build relations. Hinduja and Patchin (2008) agree with this as they found that youth with access to internet are broadly using computer-mediated methods to stay in touch mainly because it is convenient, expedient and purposed than previous means such as face-to-face interaction and telephone. Therefore, the popularity of social networking websites has seemingly redefined interpersonal communication and relationships as was known (Romn, Plistkin \& Clarke, 1997).

In this study it was found that by convenience the youth meant economical convenience and spatial convenience. This is further illustrated by the following statement by a respondent:

\section{Facebook is very economical. I mean if you have a computer and an internet connection you are all set to use Facebook. It doesn't cost you anything. But, if you try to call or sms friends it will cost you something. So one main reason why I use Facebook to keep in touch with friends is because it's free of charge.}

Youth in the selected age cohort are likely to be pursuing education rather than being employed; this gives them a reason to be careful with expenses because they are economically dependent on their parents. The domain of Facebook has a limited number of restrictions. This liberal state contributes for Facebook usage to be a main mode to maintain past and present relations. The cost of consumption through electricity bills, phone bills and internet connection bills are camouflaged in the eyes of the Facebook user. The fact that Facebook does not levy a payment for its use is what the users emphasize on. Without a source of income, it is difficult for the youth to spend money to maintain relations. Therefore, the Facebook's manifestation as free of charge is a great stimulator for them to use it. In their dependent state the hidden expenses are ignored because they are provided for by the parents.

When I moved back to Australia last year I didn't have time to call my friends to tell them that I am leaving. I logged on to Facebook on my way to the airport through my mobile and updated my status as 'leaving Sri Lanka see you all next year!' And it was much effective than spending time and money calling people. I had ten or fifteen friends commenting and replying with wishes on Facebook within the next half an hour.

This quote from a respondent illustrates how expedient it is to use Facebook. Other than being available at any part of the world, Facebook is accessible through mobile phones as well. This allows people to use Facebook even without a computer. The users can activate a feature on Facebook that sends an automated text message whenever some activity occurs in their network. For example, when a friend updates their status or comments on your Facebook page, you receive an automated text message with all the details. It assists you to access Facebook and promptly respond to the activity on Facebook. The various forms of accessibility to Facebook is a reason for the youth to find the use of Facebook as a very convenient medium of social networking.

Individuals can be linked within a social network because of many possibilities. Some of them might work or go to school together, have graduated from the same university, live in a particular city, or share an interest in a certain music artist, television show, an actor, a hobby or lifestyle. Regardless of the reasons for the connections, individuals are drawn to others with whom they can relate to (Asher \& Parker, 1989). Accordingly, social networks of persons naturally arise due to past and present life experiences and relationships, and open up opportunities for future interactions (Surra \& Milardo, 1991).

I managed to get in touch with many of my school friends through Facebook. It was hard to even recognize some of them because I haven't seen them for a long time. I managed to get back on track with many of my friends because of Facebook. 
I think everyone in my school has a Facebook account. I have found so many of my batch mates on Facebook. It's difficult to find someone without a Facebook account.

The youth join Facebook in order to be included in their peer groups that fulfill their need to belong. According to Parson (1968; cited in Samarasinghe, 1998), peer conformity is a feature of youth that is used as a tool against adult authority. Youth are more likely to adhere to the persuasions of their peers during this stage of life. With the ending of school days, the relationships with friends in school tend to be estranged. This is largely due to the lack of communication. During school, relationships are maintained because they are seen often, but once you leave school there is no common ground to meet and sustain these friendships. Facebook has presented the youth with such a common ground to communicate and sustain past and present relationships. It has become a preferred way to maintain relationships mainly because it is perceived as free of charge and easily accessible.

Individuals can quickly create their 'virtual presence' among the created virtual presence of their entire social group and can immediately and conveniently get in contact with one or all, on these social networking websites. Regardless of the physical or temporal location of the person, users can intangibly surround themselves with the online representations of friends and acquaintances allowing them to feel close to any or all of them. These online portrayals are often replicas of their real-life counterparts, and thus interacting in this manner is the next best thing to actually being with those friends in person. It may also be preferred by many due to the ease and celerity with which conversations can take place (Hinduja \& Patchin, 2008).

\section{Facebook is a good way to get others' attention when you are feeling sad or angry or happy. If you are angry with someone you can really convey that message through Facebook. And if you are feeling low you can get a lot of support through Facebook. Like last time when university closed due to some student fight, I was so upset. When I logged on to Facebook I could see many of my other batch mates have updated their frustrations on Facebook. Then we discussed about it on Facebook and shared our frustrations. Until Uni started again, we were constantly on Facebook to discuss our frustrations and to pass information on when Uni is reopening and all...}

As this respondent stated, Facebook acts as a sphere to voice out your emotions and share them with others with similar sentiments. Facebook acts as a domain that allows the youth to obtain emotional comfort from peers. Knowing that your peers are also in an equal emotional state helps you to understand and deal with your own emotions.

I use Facebook chat to tell others of difficult
emotions. As in if I feel someone did something
awkward to me which I couldn't tell to his face,
I would say it through Facebook. It is easier
because I can carefully choose the words to tell
my friend about my emotions.

Facebook has created a sphere in which the user can freely express their emotions and get support at any given time because it gives a digital map of one's offline friends rather than friends who are newly met via Facebook. This further confirms that the youth use it to maintain past and present friendships rather than using Facebook to find new friends.

The growth in internet access, speed, and computer hardware and software availability coupled with a population of youth that is increasingly being raised in front of a computer has led to social networks being replicated online (Hinduja \& Patchin, 2008). This fact points out to the social change that has taken place in contemporary societies influencing the development of web-based social networks and invariably the development of youth. The youth are widely inclined to web-based social networks because it is the icon of their epoch.

\section{ESCAPING TO AN ALTERNATE REALITY}

Berger and Luckmann (1966) taking forward the interactionist argument of Alfred Shutz, suggest that people live in a world that presents as a 'reality' due to the subjective interpretation given to it by them. Though people may have individual realities, they have one coherent inter-subjective reality that binds them together as one society. This common reality is their everyday life. Berger and Luckmann (1966) stated that 'everyday life presents itself as a reality interpreted by men and subjectively meaningful to them as a coherent world'. Another feature of this world is that it is taken for granted. As once explained, one never really think about water coming through as soon as a tap is opened until it doesn't. It is because this everyday action is taken for granted. The intersubjective reality is viewed as a world that originates in ones thoughts and actions, and is maintained as real by these (Berger \& Luckmann, 1966). 
The human consciousness is directed towards objects that are presented as a reality. The consciousness guides one through different spheres of reality. This leads one to accept that the world consists of multiple realities, such as family, workplace, television, sports and games. In Berger and Luckmanns' (1966) terms, people transit between these multiple realities every day. However, it should be noted that all the multiple realities exist within the paramount reality of everyday life.

The use of Facebook by the youth of Sri Lanka indicated that it has become a part of their paramount reality. The majority of the respondents of this study use Facebook as a daily routine. This can be interpreted as a new virtual dimension of the multiple realities spoken about by Berger and Luckmann (1966). For the young users of Facebook, it has become an intersubjective reality that they transit to because they have identified it as a realm of entertainment and a mode for interaction with their peers.

This can be illustrated with the example of logging on to Facebook via a computer or a mobile from anywhere at any time to engage in virtual games that are available. With a click of an icon, a person is transported to a world of virtual games that is inter-subjective to that person and his/her friends. A virtual symbolic presence of oneself is created in the game as a person or as an animal. A person is experiencing a separate world, another reality that can virtually replicate the paramount reality of everyday life. It is very real to that person while he/she is logged on to Facebook and engaged in the activities of the game. Once that person logs out of Facebook or is made to discontinue due to a technical failure, he/she is transported back to the mundane reality of everyday life. Facebook as a 'multiple reality' presents itself virtual to its users giving them the option of escaping to it when they want to. The thesis that this paper suggests, is that Facebook can be a multiple reality that one moves to from the world of everyday life as an alternate reality that they can escape to.

It is seen as an alternate reality that assists them to get away from the daily stresses of everyday life. Most respondents referred to Facebook as a 'separate world with its own limits and rules'. Facebook is a place where they can enjoy freedom and be in touch with people they like. For one respondent "Facebook is like a bar where all lonely people get together to get away from boredom". Hence, Facebook's provision of a space to escape to when their everyday lives takes on its toll has created a novel multiple reality.
In psychological terms, escapism means to retreat from depression or other mental anxieties. When people are generally sad or depressed, focusing on happier times or brighter things is a form of escapism that offers a healthy alternative to a rather bleak reality (Scott, 2007). Facebook is seen as a bright and happy reality to escape to, when the paramount reality is austere. This form of escapism can be healthy when it allows the people to realign themselves and approach reality with a more positive outlook. One respondent said, "Meeting your friends online and being able to converse with them makes you happy and forget stresses". Most of the respondents said that they feel much better after being on Facebook; it could be stated as a healthy escapism. However, it can be harmful when it causes a person to neglect reality and retreat from dealing with the depression or mental anxiety in a tangible and practical way. One respondent who is sitting for the Advanced Level examination for the second time said, "Facebook helps me to forget the terrible stress of A/L. When I log in, it is a different world. It keeps me away from studies". This respondent uses Facebook to get away from the stress of the Advanced Level examination. But he neglects his studies by spending more time on Facebook rather than preparing for his $\mathrm{A} / \mathrm{L}$ exams. The escapism to Facebook makes him neglect the important reality of learning. Hence, escaping to the Facebook world has adverse effects as well.

Television, movies, sports, music, books, role-playing games, the internet, computer games and recreational drugs among other items have long been associated with helping people get away from the rigors of everyday life. It is largely accepted that escapism can help people to interact within reality and cope with some of the stresses of modern life. For years people have been turning to radio programmes or science fiction programmes to envision another world and grasp at what life might be like within another experience. Nowadays, with the expansion of the internet, Facebook has become a mode of experiencing another world and cope with stress. The study revealed that people generally log on to Facebook in the night, after the hectic day has ended. All the respondents agreed that they log on to Facebook after dinner or during holidays or weekends when they have time to relax. It was said that Facebook entertains them in such a way that they feel happy by being on it. The main modes that Facebook entertains them are the virtual games, the applications, checking friends' profiles and pictures and chatting with friends online. Hence, either Facebook has taken the same footing as television or radio in the realm of escapism or it has replaced television and radio as modes of escapism because as stated by the 
respondents they use the time for television or radio to be on Facebook.

At this point one may wonder what these youth do on Facebook. As a modality of escapism, there should be some attraction that keeps them hooked on to Facebook. The finding of this study was that the prime attraction is the virtual games and applications which can be argued as virtual worlds that simulate an alternate reality to the user in this new-age multiple reality.

Baudrillard (1981) states that what is available in this age are simulations of reality, which are not any more or less 'real' than the reality they simulate. In this contemporary era where third-order simulacra dominate our lives, the image has lost any connection to real things. The reality presented through media is more real to people than the actual reality that they are a part of. One can feel closer to a person whom they communicate with through Facebook than the people whom they live with. It is not necessary to have actually met a person 'in person' to have interactions. In this virtual space one can give meaning to things that are false copies of something. Facebook becomes such a simulation of reality because its virtual representations are all imitations of what is real. For example, the virtual games and applications are virtual imitations of real life objects such as pets, farms, cafes...etc. The difference from the other media is that it presents everything in a virtual manner and allows the user to take part in that virtual simulation at that very moment. This fact makes it an alternative reality for the user, as suggested before. Facebook acts as a multiple reality that the users escape to.

The games on Facebook cater to many tastes and kinds. The majority of respondents of this study voted 'Barn Buddy' as the most popular game on Facebook at present. It is a game that allows people to have a farm on their own and harvest a crop, sell the harvest and earn money. The player can steal crops from their friends' farms and spread weeds or bugs on others' farms or help their friends to grow their farms. The official 'Barn Buddy' page on Facebook states that there are 3,849,537 active users of that game as of date ${ }^{2}$. A respondent shared how she got to know of 'Barn Buddy' as follows,

I was highly surprised when one of my friends told me to join 'Barn Buddy'. She was explaining to me how you have to grow crops and then sell the yield and how I can be her neighbour. She was so excited about it. She went on saying how much fun it is and giving me reasons to join it.
Ultimately, she forced me to join. But later on I was also hooked on it. It was as good as she told it would be.

An Advanced Level student who is a great fan of 'Barn Buddy' stated,

Once you are involved with Barn Buddy it's as if you are a farmer. You have to look after the crop, add fertilizer on time, harvest on time, look after your cattle and sheep...etc. It's as if you are transformed to a farming life. You are in a virtual farm that belongs to you and there are many things to be done around the farms. It is a separate world altogether!

The players enjoy an alternative reality that they are exposed to through 'Barn Buddy'. However, the respondents, who are unemployed and pursuing education tend to spend more time on Facebook enjoying these simulated realities than those who are employed. Those who are pursuing education has more time at hand to spend in these simulated realities than their counterparts who have work responsibilities. It was also noted that youth in their teens and early twenties are more involved in these virtual games and applications than the youth in their late twenties. This could mean that with maturity and increase of responsibility youth tend to disassociate from enjoying such alternate realities.

'Pet Society' is another such virtual game that is popular among the respondents. This game allows one to raise a virtual pet. The official page for Pet Society on Facebook (2010) states its purpose as, 'create and raise a happy pet in Pet Society! Play games, decorate your house and bring gifts to your friends' pets when you visit them. Raise your pet and enjoy many activities together-racing, fishing, gardening, and cooking! Make your pet happy by earning coins to shop and buy stylish clothing and cool furniture. In the world of Pet Society, it's nonstop fun for you and your pet!' Pet Society is promoted as a 'world' that could be defined as a simulated reality. According to the official 'Pet Society' Facebook page, there are 19,089,563 users of 'Pet Society' on Facebook as of date ${ }^{3}$.

According to an active user of this game,

Pet Society lets you raise a pet you like. You have to feed them, clean them, dress them, take them out for parties, build a house for them... basically do lot of activities with them. I log in everyday on Facebook to play with my pet.

2,3 'as of date' refers to the time when the research was done in 2009/2010. The numbers may differ with time. 
In this alternative reality, people give life to the animation of a pet and adorn it with everything and more than one would give their real life pet. As Baudrillard (1981) states it is no longer a question of imitation, nor of reduplication, nor even of parody. It is rather a question of substituting signs of the real for the real itself; that is, an operation to deter every real process by its operational double, a metastable, programmatic, perfect descriptive machine, which provides all the signs of the real and short-circuits its entire vicissitudes (Mann, 2004). By understanding the real life 'pet' as a form of a sign that is virtually substituted in the game pet society, the substitution of the real for the real itself is exemplified. The fact that the users feel very much the same towards their pets at home and about their virtual pet on Facebook makes the substitution a reality for the user.

Similar to Baudrillard's (1981) exemplification of Disneyland as a perfect model of all the entangled orders of simulation, the virtual game worlds of Facebook can also be exemplified as a model of simulation. To begin with, it is a play of illusions and phantasms: pirates, the barn, pets, crops, farm animals, houses, etc. This imaginary world is supposed to be what makes the operation successful. However, what draws the crowds is the reproduction of an alternative reality that they long to escape to. One enters in to a world that represents one's pet or a real world farm and engages in activities that are impossible to encounter within one's real life and exit from that cyberspace and re-enter the paramount everyday reality. In other words, one $\operatorname{logs}$ in, play the game for a while, and log out. In this imaginary world, numbers of virtual signs are used to specifically maintain the multitudinous affect of fake as real. This effort results in the creation of an alternative reality for users of Facebook who use these virtual world games as modes of escapism.

The applications on Facebook also contribute to the construction of an alternative reality. Though all applications on Facebook can be interpreted as simulated, there are some applications that are more definite in its contribution to the creation of a simulated reality on Facebook than others. Such applications enable the user to exchange virtual emotions, engage in predictions through fortune telling or playing a virtual sport on Facebook using a virtual team that has origins in real life.

These applications that allow the users to exchange virtual emotions give the user a chance to show their feelings virtually to their friends. As one respondent suggested,

Applications that allow you to show your emotions to others through sending gifts or some icon actually help you to do things that you may not really be able to actually do in public. For example, I can't kiss or hug my girlfriend in public but on Facebook I can kiss or hug her by sending an icon. Though everyone in our friend's lists will see my actions there are no repercussions. But if I hugged or kissed her in public in real life there will be very bad consequences.

By the use of such applications, the youth are trying to overcome the cultural constraints that are binding them to suppress their emotions. The use of Facebook has given them the space to open up their emotions and freely display them in the simulated alternate reality that the youth escape to, in order to experience things that the actual paramount reality would not permit them to.

Facebook allows you to express your emotions about others in different ways. Like in Super Poke, you can express yourself by throwing a cow at your friend. It doesn't have to mean anything. But you are connecting with that person by one or two clicks of a button. And it's funny too.

Facebook therefore has enabled space for youth to express their feelings about others through such applications. In this simulated reality, they feel as if they are expressing their emotions to other people that make them realize the interaction as real. The virtual presence of that person is felt as real during this interaction. In other words, through these applications the actual physical presence of a person is replaced with their virtual presence that is felt as real by the interacting parties. However, the respondents also stated that the virtual action could not replace the real act of interaction. It is only a good alternative to show emotions in order to overcome the cultural constraints imposed by society.

It is interesting to note that applications on astrology are also very popular among users. It could be interpreted that people are very much enticed by superstitious beliefs to be using them. This use of astrology can be interpreted as an instance where simulation of reality has taken the form of reality by alternative, in which a person takes someone else's version of reality on board as his or her own. For example, Crystal (2010) states that some people who watch soap operas for a long time develop a view of interpersonal relationships that is determined by the writers of the soap. The extreme dramatic relationships in soaps are a heightened form of reality that some people relate to as being real. Such people begin to judge social relationships and situations by this heightened reality. They can no longer see the reality of a social situation without relating it to the soap. Likewise, the users of these applications take the astrological predictions as 
real and make it a part of their own reality. Later on, they relate these predictions to every social situation of their everyday life. They judge their experiences of the everyday reality by this simulated reality. For example, if a prediction stated that a person would meet someone special soon, the user will actually anticipate meeting someone special in real life.

An excerpt from my field observation notes states,

Shashi seems to be very much involved in using
Facebook astrology applications. Over three-four
days I observed that she uses applications such
as 'Anita Predictions' 'Mystic Meg's Predictions'
and 'Amora the Love psychic'. She would use all
three applications every day. Her predictions on
one day were as follows,
Anita Prediction:
'Shashi honey, you're going to have to turn down
some invitations.'
Mystic Meg's Prediction:
'Shashi, I bring you BAD news. A nasty surprise
in red is in store for you.'
Amora the Love psychic:
'Shashi darling, happiness can be found with
someone near when you look closely and discover
the good in their heart.'
The predictions were unrelated and of course
represented no logic, but for Shashi it was a form
of comfort. She explained to me that she is a
believer of astrology and used to visit astrologers
to find out when she would get married. It is a
great worry to her as she believes that she is aging
and missing out on the marriageable age. For her
the Facebook astrology applications are a way to
keep hope that something good will happen soon.
She knows that it is not very logical but she says
she can't help but believe in it. It gives her some
consolation and hope.

The astrological applications on Facebook are used by many like Shashi daily. The Facebook (2010) statistics states that $390,745^{4}$ people use Amora the Love psychic, 598,0935 people use Mystic Meg and 1,402,1196 ${ }^{6}$ people use Anita Predictions every month as of date. These figures show how popular such applications on Facebook are among users around the world. Though the reasons for their use of applications can be subjective, the applications' predictions have an impact on the users' lives.

\section{CONCLUSION}

This paper has attempted to illuminate the main reasons that motivate the youth in Sri Lanka to use Facebook.
Youth, as Erikson (1971) points out is a conflicting age between isolation and intimacy. The main feature of this stage is the formation of intimate relationships. When people form intimate relations it is difficult to sustain them with sufficient contact because of economic reasons and spatial issues. Therefore, Facebook is an advantageous sphere for youth to make as well as sustain relations. It was evident that the youth would rather use Facebook to maintain past and present relationships rather than making new friends online. New acquaintances exchange Facebook addresses just as phone numbers or e-mail addresses. Hence, as Hinduja and Patchin (2008) pointed out in their study on web-based social networks; replicas of real life social networks are created online through Facebook. The very nature of Facebook is motivating for the youth to be using it.

The reasons for the use of Facebook though mainly falling under convenience and entertainment could be specified as follows,

- Economical convenience as Facebook is free of charge

- Spatial convenience due to the ability to access Facebook from anywhere in the world

- Expedient method to maintain past and present relations

- To gain emotional support

- To use virtual games and applications available on Facebook

- To overcome cultural constraints

It is evident from this investigation that Facebook as a simulation of reality allows the user to experience an alternative reality. Facebook contributes to the creation of this alternative reality by the available virtual games and applications that have become widely popular among the users of Facebook. When using these games and applications, the individual is transported to a multiple reality that gives the user a sense of realism while being engaged in it. The moment the user logs out of this alternate reality of Facebook he or she is transported back to the paramount everyday life. The argument established herewith is that Facebook is part and parcel of the paramount everyday life of the youth as all other multiple realities. The difference is that Facebook is a virtually simulated reality that youth transit to from the everyday life as a mode of escapism from the rigors of everyday life.

As Baudrillard (1981) has suggested in the post-modern culture, people live in a 'desert of the real,' a cultural space where television, film, and computer images seem more

4,5,6 'as of date' refers to the time when the research was done in 2009/2010. The numbers may differ with time. 
'real' than the non-media physical reality that surrounds them (Mann, 2004). With a generation of youth growing up in front of computers using Facebook to maintain their social networks contributes to this 'desert of the real' by providing a space that the users can experience things that are more actual to them rather than virtual.

\section{References}

1. Albarran, A. B. \& Goff, D. H., 2003. Understanding the Web: Social, Political and Economic Dimensions of the Internet. New Delhi: Surjeet Publications.

2. Asher, S. T. \& Parker, J. G., 1989. Significance of peer relationship problems in childhood: social competence in development perspective. Dordrecht: Kluwer Academic Publishers.

3. Baudrillard, J., 1981. Simulacra and Simulation. Translated from French by Sheila Glaser, Michigan: University of Michigan Press.

4. Berger, P. L. \& Luckmann, T., 1966. The Social Construction of Reality: A Treatise in the Sociology of Knowledge. New York: Doubleday and Company.

5. Boyd, D. M. \& Ellison, N. B., 2007. Social network sites: Definition, history, and scholarship. [online] Available at: $<$ http://jcmc.indiana.edu/vol13/issue1/boyd.ellison.html > [Accessed 01 March 2009].

6. Crystal, G., 2010. What is Hyperreality? [online]. Available at: <http://www.wisegeek.com/what-is-hyperreality.htm> [Accessed 20 February 2010].

7. Erikson, E. H., 1971. Identity and Youth and Crisis. London: Faber and Faber.

8. Facebook Website, 2009. [online] Available at: <http:// www.facebook.com/press/info.php?factsheet $>$ [Accessed 26 January 2009].

9. Facebook Website. 2010. [online] Available at: <http:// www.facebook.com/press/info.php?factsheet $>$ [Accessed 04 April 2010].
10. Garton, L., Haythornthwaite, C. \& Wellman, B., 1999. Studying On-Line Social Networks. In: S. Jones, ed. Doing Internet Research: Critical Issues and Methods for Examining the Net. California: Sage Publications.

11. Hinduja, S. \& Patchin J. W., 2008. Personal information of Adolescents on the Internet: A quantitative content analysis of MySpace. Journal of Adolescence, 31, pp. 125-46.

12. Maczewski, M., 2007. Understanding how Information and Communication Technologies matter to Youth: A network of developmental, social and technological dynamics. Ph.D. University of Victoria.

13. Mann, D., 2004. Jean Baudrillard: A Very Short Introduction. [online] Available at: <http://publish.uwo. $\mathrm{ca} / \sim \mathrm{dmann} /$ baudrillard $1>$ [Accessed 30 March 2010].

14. Patton, M. Q., 1990. Qualitative Evaluation and Research Methods, 2nd ed. New Delhi: Sage Publications.

15. Romn, C. T., Pliskin, N. \& Clarke, R. J., 1997. Virtual communities and society: Towards an Integrative Three Phase Model. International Journal of Information Management, 17, pp. 261-70.

16. Samarasinghe, G., 1998. Some thoughts on the Sri Lankan Family Exposed to Armed Conflict and the Impact on the Psychological Well-Being of Youth. In: S. T. Hettige, ed. Globalization, Social Change and Youth. Colombo: German Cultural Institute. pp. 44-60.

17. Scott, V., 2007. What Is Escapism? [online] Available at: <http://ezinearticles.com/?What-isEscapism?\&id=897426> [Accessed 20 February 2010].

18. Surra, C. A. \& Milardo, R. M., 1991. The Social Psychological Context of Developing Relationships: Interactive and Psychological Networks. In: W. H. Jones and D. Perlman, eds. Advances in Personal relationships. London: Jessica Kingsley Publishers Ltd. 